Youth and young adults with mental health conditions can be found in the case loads of multiple state agencies. However, such state agencies (e.g., Education, Mental Health, Vocational Rehabilitation, Medicaid, etc.) often lack a unifying vision or plan to coordinate efforts across agencies.

This tip sheet is based on the Transitions RTC's work with the disability serving state agencies of Delaware. It provides guidance to states on how to develop a strategic plan to bridge disconnected agencies to support youth and young adults with mental health conditions.

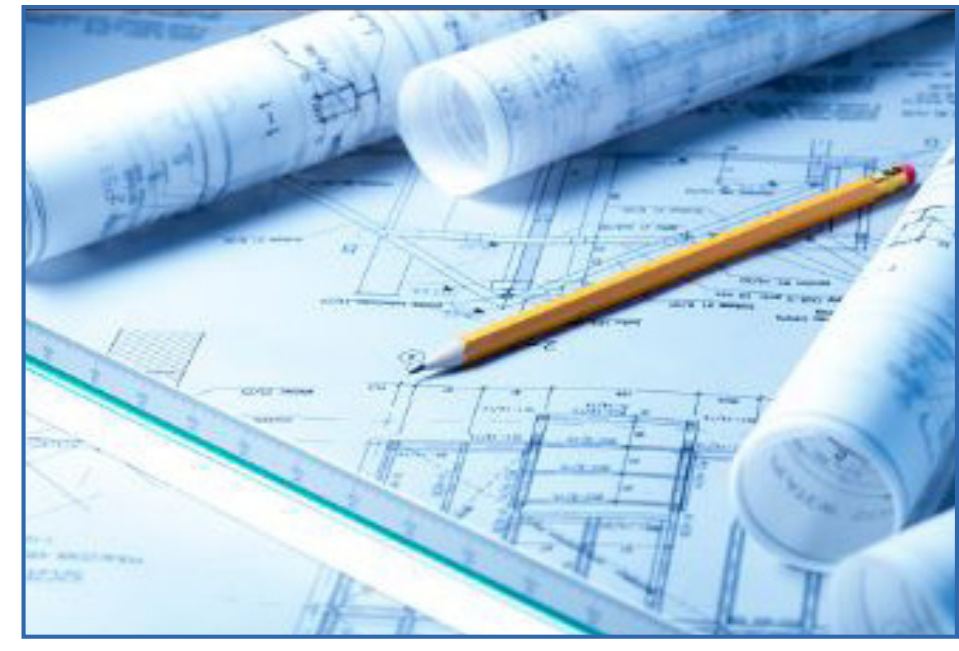

\title{
What is a Strategic Plan?
}

A strategic plan describes an organization's priorities, long-term goals, strategies, and tasks to achieve the identified goals often for a three to five-year time frame. A strategic plan should include:

- A clearly defined mission or vision statement that will guide your inter-agency collaborative initiative;

- An outline of goals, objectives, and strategies that break down your vision into specific tasks that can be worked on by different individuals or groups;

- An assessment of current resources which should include finances, personnel, knowledge, abilities, and other factors; and

- A strategic analysis or critical thinking about how to use all of the available resources to develop inter-agency collaboration. ${ }^{1}$

\section{How to Inform and Develop a Strategic Plan}

\section{What to Do}

\section{What We Did}

\section{Identify a "Champion"}

A "Champion" is the key to facilitating change. The "Champion" is an active member in the entire change process and brings everyone together. ${ }^{2}$
We garnered a well-respected "Champion" to help bring together diverse groups of stakeholders. In our case, the "Champion" was the Director of Delaware's state agency of Vocational Rehabilitation. 
Form a Steering Committee

The steering committee should involve agency Directors or high-level delegates from the multiple agencies that service youth and young adults with serious mental health conditions. The steering committee's role is to provide guidance on data collection and planning, and to review and comment on draft documents.
We assisted Delaware state agencies in forming a steering committee that held monthly planning meetings. The Delaware steering committee involved agency Directors and high-level delegates from state agencies such as Vocational Rehabilitation, Behavioral Health, Special Education, Higher Education, Labor, Medicaid, and Private Mental Health Providers.

\section{Conduct a SWOT Analysis}

A Strengths, Weaknesses, Opportunities, and Threats (SWOT) analysis identifies and assesses the internal and external factors that can impact your organization's success and sustainability. Strengths are internal positive factors in your agencies that will assist in inter-agency collaboration. Weaknesses are internal factors that are barriers to reaching your organization's goals. Opportunities are positive factors external to the involved agencies. Threats are the negative factors that are external to all of the agencies.
The Transitions RTC used a Strengths, Weaknesses, Opportunities, and Threats (SWOT) analysis to inform an environmental assessment/ scan for Delaware's strategic planning process. The SWOT analysis for the Delaware project was derived from key informant interviews and document/website reviews.

\section{Gain Input from Stakeholders}

Query an expanded group of key informants on aspects of a strategic plan including guiding vision, values, beliefs, priorities, goals, strategies, and tasks/activities to meet the priorities for planning based on the results of the SWOT analysis. Be sure to include the input of youth, young adults and family members.
Based on the results of our SWOT analysis, our team conducted a web-based survey for an expanded group of key informants to refine the plan's components. Survey respondents were asked to rank the importance of each topic for strategic planning.

\section{Conduct a Strategic Planning Summit}

While at this summit, attendees should work together to develop a strategic plan with the following components: vision, values, beliefs, priority areas, goals, and strategies by topics. Conduct an interactive planning session with representatives and directors of the multiple agencies that serve youth and young adults with mental health conditions.
At our one-day Delaware summit, we had four facilitators to run the meeting. We had a planned agenda for the day. Participants moved to small preassigned group tables to develop the strategic plan goals and strategies (tasks). We used an interactive round table planning structure called the World Café method that ensures a collaborative, interactive planning process.

(See: www.theworldcafe.com/key-concepts-resources/ world-cafe- method/). 


\section{Develop Strategic Plan Components Through a Summit}

Summits can be organized and facilitated by experienced strategic planners and an administrative team. At a summit, attendees work together to develop a strategic plan and plan components.

\section{Identify priority areas and subtopics for planning based on analysis and information gathering}

Strategic priority areas are what a group or organization wants to achieve. They are not goals, but high-level objectives that were determined to be of the most importance to achieve the organization's mission.
Attendees at the Delaware summit identified three priority areas: Communication \& Collaboration, Funding \& Policy, and Service Capacity. Using data collected with the internet survey, subtopics were decided on and grouped with the appropriate priority area.

\section{Develop a long-term (3-5 year) goal for each priority area}

A goal is a projected state of affairs that a person or a system plans or intends to achieve. It identifies in broad terms how your initiative is going to change things to solve the problem you have identified. It's the result that your agencies want to achieve.
At the Delaware summit, participants broke into smaller groups to draft goals. The group facilitators asked participants to think about the priority area, write down some words/ideas, and then share ideas with the group. Facilitators captured key themes and structured the themes into a finalized goal statement.

An example of one of the goals developed was: The education system and behavioral health treatment providers for youth and young adults will communicate with students and their families on how to access mental health resources through collaborative, individualized service planning that leads to the development of the student's career pathway. ${ }^{2}$

\section{Develop strategies for each finalized goal}

A strategy describes your approach to getting things done. It is less specific than action steps but tries broadly to answer the question, "How can we get from where we are now to where we want to be?"3 A good strategy will take into account existing barriers and resources (people, finances, time, and materials) and determine how you will achieve your goals through action. ${ }^{3}$
We had participants write draft strategies individually, share/compare with a partner, and then share/compare in a large group. Each facilitator wrote down the ideas and grouped common ideas together. The attendees worked together to refine and clarify the strategies for each of the goals.

During the Delaware summit, Child and adult mental health was identified as a subtopic for the goal listed in the previous section. The strategies developed to accomplish this goal and subtopic were:

1. Educate child behavioral health treatment providers about transition support services.

2. Develop an advisory council with members from public and private behavioral health agencies or collaborate with an existing council. 


\section{Develop an Implementation Plan}

An implementation plan is a management tool designed to illustrate, in detail, the critical steps in developing and starting a new program or project. It identifies the actions, responsible parties, and time frames needed to achieve the plan's objectives. An implementation plan is an iterative process that allows a group to make changes if any roadblocks or challenges come up. This document ensures that all parties involved in the project or program are on the same page. To be successful an implementation plan requires a long-term multi-level approach. ${ }^{4} \mathrm{An}$ implementation plan should include an evaluation piece to see how the new project or program is doing.
Here is an example of an implementation plan based on the Delaware Summit:

Strategy 1 - Develop an awareness campaign through marketing and training about youth and young adults with mental health conditions and the importance of employment as an integral component of individual and community health.

\begin{tabular}{||c|c|c|}
\hline $\begin{array}{c}\text { Steps for Strategy 1 } \\
\text { of Goal 1 }\end{array}$ & Leaders Names & Time Frame \\
\hline $\begin{array}{l}\text { 1. } \\
\text { Develop key } \\
\text { message for } \\
\text { awareness } \\
\text { campaign }\end{array}$ & Joe Smith & $\begin{array}{c}\text { January - } \\
\text { March }\end{array}$ \\
\hline \begin{tabular}{|} 
2. \\
Choose \\
modality for \\
awareness \\
campaign
\end{tabular} & Jane Doe & April - June \\
\hline
\end{tabular}

\section{Conclusion}

State agencies understand the urgent need to improve the educational and vocational outcomes of youth and young adults with serious mental health conditions. Most individual state agencies have numerous initiatives that address this unmet need. But usually there is no unifying vision to guide the disparate efforts of these agencies, and efforts across agencies are not well coordinated. This tip sheet offers guidance on how to develop a strategic plan to bridge these disconnected agencies to improve the lives of the families, youth and young adults that they serve.

\section{References}

1. Pakroo, P. (n.d.). Create a Strategic Plan for Your Nonprofit. Retrieved from http://www.nolo.com/legal-encyclopedia/createstrategic-plan-nonprofit-29521.html

2. Ellison, M. L., Smith, L. M., Swensen, R., \& Marrone, J. (2017). Delaware Division of Vocational Rehabilitation Inter-agency Summit and Strategic Plan for Improving Employment Outcomes among Youth and Young Adults with Serious Mental Health Conditions. Worcester, MA: University of Massachusetts Medical School, Department of Psychiatry, Systems and Psychosocial Advances Research Center (SPARC), Transitions Research and Training Center.

3. Health Resources in Action, Inc. (2015). Planning Session Facilitators Guide.

4. Fixsen, D., Naoom, S., Blase, K., Friedman, R., \& Wallace, F. (2005). Implementation Research: A Synthesis of the Literature. Tamps, FL: University of South Florida, Louis de la Parte Florida Mental Health Institute, National Implementation Research Network.

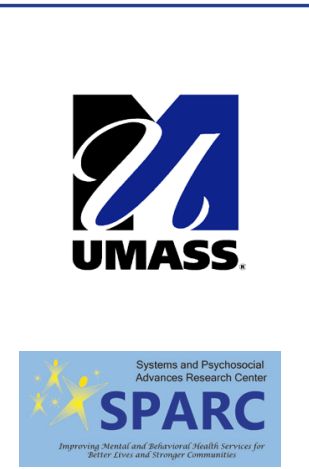

Suggested citation: Ellison, M., Swensen, R., \& Logan, D. (2017). Blueprint for Building Inter-Agency Collaboration through Strategic Planning: Supporting the Employment of Youth \& Young Adults with Serious Mental Health Conditions. Worcester, MA: University of Massachusetts Medical School, Department of Psychiatry, Systems and Psychosocial Advances Research Center (SPARC), Transitions Research and Training Center.

This publication can be made available in alternative formats upon request through TransitionsRTC@umassmed.edu

The contents of this brief were developed under a grant with funding from the National Institute on Disability, Independent Living, and Rehabilitation Research, and from the Center for Mental Health Services of the Substance Abuse and Mental Health Services Administration, United States Department of Health and Human Services (ACL Grant\# 90RT5031, The Learning and Working Transitions RRTC). NIDILRR is a Center within the Administration for Community Living (ACL), Department of Health and Human Services (HHS). The contents of this brief do not necessarily represent the policy of NIDILRR, ACL, HHS, or SAMHSA and you should not assume endorsement by the Federal Government.
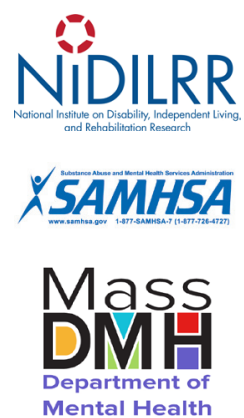